\title{
Optimization of the Service for Applying for CSC Scholarship in Beijing University of Technology under the Construction of "Double-first class" Universities
}

\author{
Wen Gu, Yufan Sun*, Dengmei Ji, Yi Li \\ Beijing University of Technology \\ Beijing 10005
}

\begin{abstract}
The implementation of the Chinese Government Scholarship programs is an important measure to cultivate innovative talents with international vision, and will be an important driving force to speed up the integration of the teaching and scientific research level with the international level. As the main body of the "Construction of High level Chinese Government Scholarship programs", colleges and universities play a more and more important role in guaranteeing the benefit of studying abroad designated by the government and doing a good job in the service of the postgraduate students. In the face of the new situation of studying abroad, Beijing University of Technology has constantly adjusted the service management of the public school students in recent years. Instead of providing simple service, it has gradually changed into an active, long-term and comprehensive service. It has achieved good results and has effectively promoted the cultivation of the outstanding talents.
\end{abstract}

Keywords-Chinese Government Scholarship programs; Cultivation of postgraduates; Internationalization of talents

\section{THE RESEARCH BACKGROUND OF THE CHINESE GOVERNMENT SCHOLARSHIP PROGRAMS}

In order to implement the strategy of invigorating the country with science and education and the strategy of talent power, to meet the needs of the creative state construction strategy for talents, and to train the top innovative talents in all walks of life after several years, the Ministry of Finance and the Ministry of education has set up a " project of the Chinese Government Scholarship for building high level universities in China ", approved by the State Council in 2007. The implementation of this project has greatly increased the number of postgraduate students studying abroad.

In January 2017, the Ministry of education, the Ministry of Finance and the national development and Reform Commission issued:" the Comprehensive Promotion of the Implementation of the World's First-class Universities and First-rate Disciplines (Provisional)(2017)[No.2]" [1], and explicitly proposed to "promote the overall promotion of higher education in our country in the cultivation of talents, scientific research, social services and cultural inheritance and the comprehensive strength of the new and international exchanges and cooperation. "To cultivate top-notch innovative talents with international vision is the fundamental task of "double first class" construction in colleges and universities.

Graduate education is the main way to train high-level talents. It is an important part of the national innovation system, and shoulders the important task of training high-level talents. The national postgraduate study abroad has become a national strategy and has become a national brand. The management and service of overseas students are also receiving increasing attention. According to the practice in the work, this paper makes some discussions on the selection, dispatch, external management and return work of the public students, and puts forward some corresponding countermeasures in order to achieve the overall goal of expanding the scale of studying abroad, improving the level of teachers and guaranteeing the development of the subject This paper, taking the Beijing University of Technology in recent years to implement the " project of the Chinese Government Scholarship for building high level universities in China" as an example, through the summary and induction of the work experience of the graduate students studying abroad in the public school of the Beijing University of Technology, combined with the summary and statistics of the return of the returnees from the public school. In view of the existing problems in the service of postgraduate student study in Colleges and universities, some suggestions are put forward, which will provide a reference for the better development of the service work of the postgraduate students in the future, to promote the cultivation of the top talents and to improve the efficiency of the postgraduate students studying abroad. 


\section{CONCRETE PRACTICE OF BEIJING UNIVERSITY OF TECHNOLOGY's CSC POSTGRADUATE PROGRAM}

In the international student service and management of the postgraduate project, Beijing University of Technology has mainly done the following aspects:

\section{A. Building platform}

On the one hand, through the inter school network and the instant communication platform: the graduate students can communicate with each other from the preparatory stage. Every graduate student is the beneficiary and the service provider, which can effectively solve many common problems. On the other hand, the management department of our school can also pass the exchange platform. Important information is released to understand and grasp the situation of public postgraduates and improve their work efficiency. It can also rely on the platform to publish related matters, work arrangements and requirements on the public school, and answer the problems encountered during the postgraduate application process and the public school, and can make a good interaction.

\section{B. Improving the training system and strengthening the education of safety responsibility}

Relying on the Ministry of education's overseas study and training center, centralized training is conducted before the public graduate students going abroad. The contents of the training include both the interpretation of public policies and regulations, as well as special lectures on the international situation and China's foreign policy. There are both public and overseas doctoral students' experiences and experiences, and young teachers returning home teach how to make use of foreign resources for scientific research. Through the training, the postgraduate students can more intuitively understand the processes and matters of attention sent out. More importantly, it is more important to further promote the improvement of the public school students' sense of responsibility for studying abroad, making them fully aware of the responsibilities and obligations of the national public students. In addition, the implementation of the public postgraduate program enables a large number of graduate students to go abroad for further studies. On the one hand, many graduate students have just completed the master's stage of study, even some of the direct students have just graduated from the undergraduate level. The trend of the junior graduate students is becoming more and more obvious. On the other hand, most of the public postgraduates are the first time to go out of the country, and their experience is limited. In view of this, our school first has strengthened the safety responsibility education outside the country, enhanced the public security graduate student's safety consciousness, the self-defense consciousness. It is important to emphasize that the postgraduate students of the school of education keep a clear mind in the front of the great and the other, and it is particularly important to learn to think and solve the problems from a variety of perspectives. Secondly, the content of education has become more practical. For example, lectures on Chinese and Western culture, etiquette and customs, lectures on health knowledge, etc., so that public postgraduates can adapt to overseas life as soon as possible.
Thirdly, in view of the relatively weak psychological ability of the public postgraduate students, our school invited the teachers of the mental health center to hold special lectures to improve the psychological adjustment ability of the postgraduate students in the outside world, to realize the safe study of the public postgraduate students and to study in a healthy way.

\section{Strengthening the construction of the system and optimize the management process}

First of all, Beijing University of Technology has formulated a series of management documents on public postgraduate projects, involving various aspects such as assessment, student status management, award grants and so on. By organizing the forms of sending out instructions, the public school students are organized to concentrate on their study. From the policy interpretation, ideological guidance, to ensure that graduate students knows the responsibilities and obligations. The responsibilities, rights and benefits of the three parties of graduate students, tutors and schools are made clear by the humanistic management concept, which ensures the orderly conduct of the whole public school process.

Secondly, we should strengthen effective communication and cohesion between relevant departments at the school level so as to realize the sharing of information among public postgraduates. For example, the process of sending out postgraduates, lodging arrangements, and postponed graduation, etc., try to optimize the process and simplify procedures. These have made the CSC project really become a key project of various departments in Beijing University of Technology.

\section{THE INTERNATIONALIZATION OF BEIJING UNIVERSITY OF TECHNOLOGY}

With the opportunity of international talents training, we can promote the training of multi-channel international joint talents, and through academic exchanges, we can get to the forefront of international academic topics and broaden their horizons.

\section{A. Selection, dispatch and management of CSC postgraduates}

In 2017, our university was awarded 33 joint training of 33 doctoral graduate students from the CSC program, and 1 student from the national public school to develop a master's degree. They went to the United States, the United Kingdom, Canada, Australia and other well-known universities to exchange learning. We should strengthen the propaganda work, standardize the selection and dispatch the management process of the national postgraduate students, and strengthen the whole process management of the national postgraduate school selection, the foreign study and the return service.

In 2018, our school was granted 1 national doctoral candidate from CSC program. It has created a zero breakthrough for the project in the last 10 years. 


\section{B. Joint training of school level}

In 2017, a total of $17 \mathrm{PhD}$ students and 19 graduate students went abroad to participate in scientific research or joint training. Among them, relying on the intercollegiate agreement, 5 students went to the National Institute of technology for a master's degree in France. 20 postgraduates were enrolled in the school short-term joint training program and sent on schedule, and 11 graduate students were jointly trained under the assistance of the tutor or the other party.

\section{Participation in international academic conferences}

In 2017, a total of 144 doctoral students and 60 master graduates went abroad to attend high level international conferences, of which 81 doctoral students received financial support from our university "doctoral graduate students abroad to participate in international high-level international conference support program" and made oral reports at the high level international academic conference.

\section{Plan for the development of the international ability of the young tutors}

This year, the first batch of the project of the first batch of youth tutor's international capacity development program was carried out. 31 young tutors have been constantly groping and maturing in 3 years, constantly understanding international policies and rules, improving the ability of intercultural communication, promoting the training of talents, and promoting the international impact of our school. In 2017, on the basis of learning from the first batch of experience, we completed the second batch of young mentors' international capacity development project selection.

\section{PROBLEMS IN THE SERVICE OF POSTGRADUATE STUDENTS STUDYING ABROAD}

At present, the types of CSC projects are increasing, the scale of public personnel is expanding, and the age structure of students is becoming younger, and the management is facing new challenges [2]. In order to solve the current situation of the public postgraduate student management service in the present stage, we have made a survey of the public school students who have returned home from Beijing University of Technology, and found that there are three main problems in the work of the public school students studying abroad.

\section{A. The application guidance work of the public postgraduate should be strengthened}

After many years of implementation, the project has produced great repercussions in college graduate students, and many graduate students have even applied for the public postgraduate programs as the first choice for studying abroad. Although schools are more detailed in providing public information on studying abroad, they still lack effective guidance in the process of selecting foreign universities and contacting foreign tutors. Most graduate students are in contact with foreign tutors by their own. There is also a phenomenon that foreign instructors are kinds of "indifferent" to the doctoral students who are jointly trained outside the country. How to realize the precise study of public postgraduate students and give full play to the role of CSC projects are the three concerns of schools, colleges and mentors.

\section{B. The management of postgraduates should be strengthened during the period outside.}

Since the implementation of the public postgraduate project, the reform and innovation have been carried out on the basis of perfecting the selection method, formulating the principle of electing, optimizing the selection of personnel and correcting the evaluation criteria. A set of more perfect talent selection mechanism has been established. It not only embodies the openness, fairness and fairness of the selection, but also ensures the quality of the selected personnel. However, at the present stage, colleges and universities are still lack of regular evaluation of the public school graduate students in foreign study and scientific research, and their supervision and management are slightly less than the public selection mechanism. Some graduate students have no pressure during their studies outside the country. Some graduate students pointed out that "The national public supervision mechanism is insufficient. Most of the time, graduate students consciously finish their tasks, and regular reports go through the motions. Can we understand the status quo, difficulties and care of graduate students through irregular spot checks? In particular, for the joint training of doctoral students, "foreign tutors have no supervision obligations, if the public school graduate students are not selfconscious: it is very easy to be in the state of unsupervised. It is suggested that the consulate should set up a special person for a random investigation by telephone and mail to ask for a definite supervision by a foreign tutor."

\section{The employment service of the postgraduates needs to be strengthened}

In accordance with the plan of the National Committee for studying abroad, more than ten thousand students have received funding from national public projects each year for joint training or studying for doctorates abroad, and thousands of public postgraduates have come back to China [3]. The CSC project advocates studying abroad and serving the country after graduation. The restriction of policies and regulations determines that public postgraduates are not allowed to come and go freely. However, how to ensure and attract these outstanding talents to return to employment smoothly, to learn to use and develop their abilities, to provide intellectual guarantee for the national economic and social development, is a special issue to be paid attention to in the implementation of the national public postgraduate project. Most graduate students think that employment is lack of effective guidance after studying abroad, and the choice of work is random. Many graduate students are not clear about their career development in the future. A graduate student who has obtained a Ph.D. degree has failed to find any intention of employment. The above problems put forward new requirements for the future study of college students. The service work of the postgraduate students should run through the whole process, and it is necessary to guide the employment work of the public postgraduates after their return. This is also 
an important link to improve the long-term efficiency of the study students in the public school.

\section{A PROPOSAL FOR PUBLIC SCHOOL STUDENTS TO STUDY ABROAD}

Good management services are conducive to the public graduate students' reassuring scientific research, telephone and mail form a random survey request for a certain supervision by foreign tutors "and so on, which also helps them to complete their study as soon as possible. Many graduate students believe that the management and service during their stay abroad have a significant impact on their willingness to return. In order to further the good service of studying abroad, it is necessary to change the traditional concept, to change the passive response to active service in the service of studying abroad, and to extend the work of studying abroad to various work related to studying abroad [4]. In view of this, we make the following suggestions:

\section{A. Changing ideas, locating functions, active service}

The implementation of the CSC postgraduate project is the key field and priority subject, which is closely related to the National Medium and Long Term Science and Technology Development Plan Outline, and is to train the top and innovative talents for the country. Therefore, colleges and universities should guide the development of this unit and the needs of talent training, and strengthen the guidance in the process of applying for foreign schools and tutors in foreign countries. At the same time, it focuses on the psychological and emotional needs of public postgraduates. One of the main difficulties encountered by many graduate students is loneliness. The postgraduate students, especially the postgraduates who have studied the doctorate, are in a long time outside, and the double pressure of learning and life can easily lead to their psychological fluctuations and negative emotions. This requires colleges and universities not only to send letters and greetings during the traditional festivals, but also to strengthen their ties with them at ordinary times. For example, it is of great benefit to ensure the smooth study and scientific research of the postgraduate students if some postgraduates can be regularly sent to the materials that reflect the positive energy of the overseas students are arranged into monthly or quarterly publications, which are sent to the public postgraduates in the form of mail.

\section{B. Perfect mechanism, periodic evaluation, long term service}

How to realize the process supervision of the public postgraduates, especially the joint training of doctoral students, to realize the optimization of export, and to use the country's money well and manage well is an urgent problem to be solved in front of us. At present, domestic universities generally pay little attention to the evaluation of public postgraduates, especially joint training doctoral students. With the expansion of the scale of public postgraduate and the increasing number of projects, it is unrealistic to rely solely on the strength of the overseas student Fund Committee and the embassies. The doctoral students of joint training rely on sending colleges and domestic tutors to conduct assessment and send out the research progress report submitted by postgraduates regularly and endorsed by foreign tutors to the embassies and the colleges and universities, and to assess the progress of their scientific research by sending universities and the tutors of the students and feed back to the national study foundation of China. The graduate students random sample reports can be submitted to the experts organized by the CSC. For excellent students, it is suggested that the students should be rewarded in the form of scholarship or to encourage them in the form of certificates, praise letters and other forms. For the students who are not qualified, the students are advised to return to China in advance. At the same time, the relevant management departments can also allocate the public quota for the next year according to the assessment of the postgraduate students of colleges and universities each year, and evaluate the sustainable development of the public projects effectively so as to realize the rational utilization and distribution of the national educational resources. Through the implementation of these measures, we have formed and perfected the selection, assessment and elimination of the operational mechanism for the public postgraduate projects to ensure the implementation of the project.

\section{Preferential recommendation, policy support and comprehensive service}

In the service of returning and employment of public postgraduates, the CSC and the National Student Service Center and the embassies have done a lot of work. Such as setting up a special column on the website of various departments, publishing employment information, holding video recruitment meetings, and so on, it provides a good channel for public personnel to understand the employment information in the country outside. In addition, the author thinks that colleges and universities can carry out the following two aspects:

First, take the initiative and choose the best. Through the improvement of the evaluation mechanism of public expatriates, foreign embassies and consulates and CSC can understand and grasp the overall situation of public postgraduates. And then we should actively recommend students with excellent achievements in scientific research, especially in Chinese western colleges and universities, and scientific research institutes, or to actively contact the post doctoral mobile stations in universities or scientific research institutes in China. In addition, colleges and universities can also bring the postgraduate students of the doctoral degree into the reserve teachers. For example, our school will bring the returnees to the teacher's reserve team construction plan, and the selection and employment priority recruitment.

Second, create an atmosphere for innovation and entrepreneurship, and promote the transformation of scientific research achievements. Public returnees have strong ability of innovation and scientific research, and are important forces for universities to carry out "innovation and entrepreneurship". By making support policies, colleges and universities provide various conveniences and create a creative and entrepreneurial atmosphere, which will help them transform advanced scientific research results, promote the industrialization of scientific research results, and provide support for the 
effective docking of innovation chain and industrial chain. For example, our school provides practice and support for the innovation and entrepreneurship of the graduate students, through the establishment of a training platform for the integration of production and learning, and the transformation and incubation of innovation to entrepreneurship.

\section{CONCLUSION}

The "double first class" construction must have the firstclass quality of personnel training, and we must comprehensively enhance the comprehensive quality, international vision and scientific spirit of postgraduates. The implementation of the national public school graduate program has provided high quality talent resources for the construction of teachers in our school and other colleges and universities in China. A considerable number of public returnees have been returnees to teach in our school and other colleges and universities, and enrich the teachers' team [5]. The important development strategy of postgraduate students studying abroad combined with national talent cultivation came into being. This paper has made a systematic study on the quality management of postgraduate school students, designed the structure of quality management system, and put forward the strategy of quality management for the graduate students to study abroad, which can promote the quality of students studying abroad and the efficiency of the public school.

\section{REFERENCES}

[1] The Ministry of education, the Ministry of Finance and the national development and Reform Commission. The Comprehensive Promotion of the Implementation of the World's First-class Universities and Firstrate Disciplines (Provisional): (2017) No.2 [A/OL]. (2017-0127).http://www.gov.cn/xinwen/2017-01/27/content_5163903.htm\#1.

[2] Chou, P.F., Optimizing the service of studying abroad, promoting the cultivation of top talent. Academic degrees \& Graduate Education, 2017 (7): 21-24

[3] Promoting the innovation of the training mode of the shortage of talents, Promoting the development of national public study [J]. World education information, $2013: 54-56$

[4] Feng, J., Chen, H.F., The improvement of the public school and the management work [J]. Meitan Higher Education, 2012, 30(6):107-110.

[5] Hu, F., Hu, X.Y., Jia, A.Y., the effect of Preliminary exploration about doctoral graduate students from the CSC program [J]. Academic degrees \& Graduate Education, 2012 (6): 51-55. 